\section{Lars Börjesson Lars-Erik Lindgren \\ Division of Computer Aided Design, Luleå University of Technology, 97187 Luleå, Sweden}

\title{
Simulation of Multipass Welding With Simultaneous Computation of Material Properties
}

Multipass butt welding of two $0.2 \mathrm{~m}$ thick steel plates has been investigated. The objective is to calculate residual stresses and compare them with measured residual stresses. The material properties depend on temperature and temperature history. This dependency is accounted for by computing the microstructure evolution and using this information for computing material properties. This is done by assigning temperature dependent material properties to each phase and applying mixture rules to predict macro material properties. Two different materials have been used for the microstructure calculation, one for the base material and one for the filler material. [DOI: 10.1115/1.1310307]

\section{Introduction}

Simulating of multipass welding for calculation of residual stresses has been carried out for three decades and by different researchers, see for example Karlsson [1]. The material modelling is important for accurate computational models. Temperature dependent properties are used in most welding simulations. This is a simplification that is not appropriate for ferritic steels with their pronounced phase transformations. This makes the material properties dependent on temperature and temperature history. The method used in this study to account for the temperature dependency of the material properties is to calculate microstructure evolution and assign temperature dependent material properties to each phase. The phase properties are combined using a linear mixture rule to macro material properties. This approach has been applied to multipass butt welding of $0.2 \mathrm{~m}$ thick steel plates where 27 weldpasses were laid. Calculation of residual stress shows a good agreement with experimental values.

\section{Simulation of Thermomechanical Processes}

The material is exposed to different temperature histories during multipass welding. Rapid heating when the weld arc passes the material and subsequent cooling. Austenite will form during heating if the temperature becomes high enough and it will decompose during cooling. Ferrite will form during this decomposition and may be followed by pearlite, bainite and martensite. These phase transformations are associated with change in material properties, latent heats, volume changes etc. This will affect the thermal and mechanical analyses. The couplings are shown in Fig. 1 and explained in Table 1.

A fully coupled thermal, metallurgical and mechanical model (TMM) accounts for all couplings in Fig. 1 and Table 1 between microstructure evolution, thermal field and mechanical field. Inoue and Wang [2] performed a fully coupled TMM simulation of a single pass weld but they give very little information about the material properties, procedure and results. A coupled thermal and metallurgical analysis with subsequent mechanical analysis was made by Bergheau and Leblond [3]. They accounted for latent heat and phase dependent thermal properties and transformation plasticity. The model used in this study is a reduced coupled thermal, metallurgical and mechanical analysis where only the couplings denoted by solid arrows in Fig. 1 are accounted for.

2.1 Microstructure Evolution. The microstructure evolu-

Contributed by the Materials Division for publication in the JOURNAL OF ENGINEERING MATERIALS AND TECHNOLOGY. Manuscript received by the Materials Division May 11, 1999; revised manuscript received March 14, 2000. Associate Technical Editor: E. Busso. tion is computed from the thermal history. The microstructure algorithm of Oddy et al. [4], computes microstructure evolution for arbitrary thermal histories. It is limited to hypoeutectoid steels. The different phases considered are austenite, ferrite, pearlite, bainite and martensite. The theory of calculation of the microstructure is based on a theory of Kirkaldy and Venugopalan [5]. The grain growth is also computed. The algorithm has been extended by Oddy et al. [4] regarding the austenization model. Two austenization models are available. The simplest model, used in this study, assumes that austenite is formed instantaneously. The other model separates the formed austenite into three different fractions of carbon content. See Oddy et al. [4] for further details. However, the model does not include other phase changes like for example the formation of $\delta$-ferrite. Neither is any advanced solidification kinetics accounted for. The release of heat of fusion is linearly distributed between the prescribed $\mathrm{T}_{\text {solidus }}$ and $\mathrm{T}_{\text {liquidus }}$. The relations of Kirkaldy and Venugopalan [5] can describe a isothermal transformation diagram with twelve coefficients. These coefficients have been extracted from a TTT-diagram for a material similar to the base material. Verification of the code has been done by simulating different cooling situations from $900^{\circ} \mathrm{C}$ to $100^{\circ} \mathrm{C}$ and compare the calculated phase fractions with measured from a CCT-diagram. The result from the comparison for the base material is presented in Börjesson and Lindgren [6]. The twelve coefficients have also been extracted from a TTT-diagram for the filler material but no comparison with CCT curves was done for this material due to no measurements were available.

The material in the two steel plates is according to Swedish Standard, SS 2134, with chemical composition of 0,12 percent C, 1,42 percent $\mathrm{Mn}, 0,36$ percent $\mathrm{Si}, 0,017$ percent $\mathrm{Ni}, 0,044$ percent V, 0,003 percent Mo, 0,014 percent Ti, 0,038 percent Al, 0,013 percent $\mathrm{S}, \mathrm{Cr}$ and $\mathrm{P}$. They were butt welded together using submerged arc welding. A filler with chemical composition of 0,1 percent $\mathrm{C}, 1,25$ percent $\mathrm{Mn}$ and 0,5 percent $\mathrm{Si}$ was used.

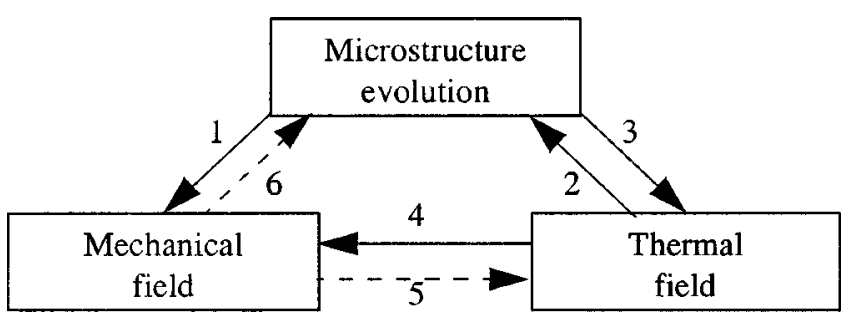

Fig. 1 Coupling between thermal field, mechanical field and microstructure evolution 
Table 1 Couplings according to Fig. 1

\begin{tabular}{cl}
\hline \hline Coupling no. & \multicolumn{1}{c}{ Remark } \\
\hline 1 & $\begin{array}{l}\text { Material properties depend on the phase fractions } \\
\text { Volume change due to phase transformations } \\
\text { Transformation induced plasticity }\end{array}$ \\
2 & $\begin{array}{l}\text { Microstructure evolution is based on thermal history } \\
\text { Microstructure evolution affects the thermal field by latent }\end{array}$ \\
3 & $\begin{array}{l}\text { heat and microstructure dependent material properties } \\
\text { Thermal expansion and temperature dependent material }\end{array}$ \\
5 & $\begin{array}{l}\text { Mechanically generated heat } \\
6\end{array}$ \\
\hline \hline
\end{tabular}

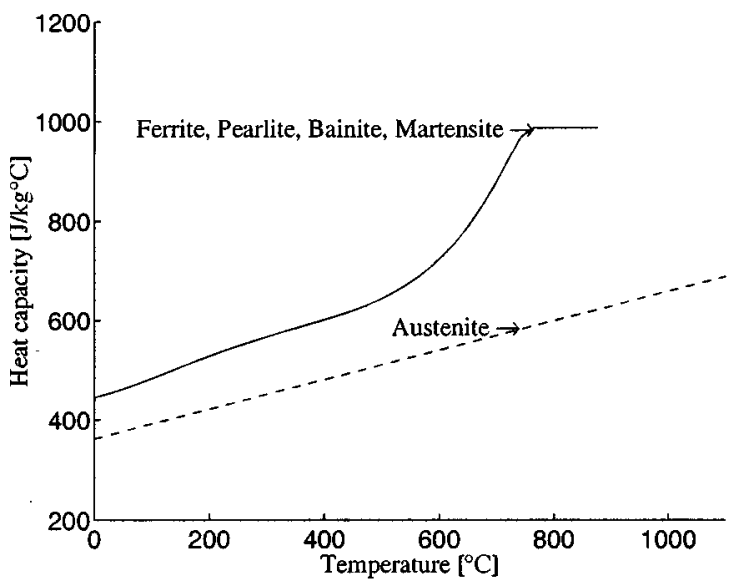

The difference in the chemical composition of the filler and the plate is accounted for by the microstructure model. The temperature for start of austenization in the equilibrium ferrite-iron diagram, $\mathrm{A}_{\mathrm{e} 1}$, is $730^{\circ} \mathrm{C}$ in the plate and $725^{\circ} \mathrm{C}$ in the weld metal. The austenization is complete at $\mathrm{A}_{\mathrm{e} 3}$. It is computed to $850^{\circ} \mathrm{C}$ for the plate and $875^{\circ} \mathrm{C}$ for the weld metal. The martensite start temperature is computed to $410^{\circ} \mathrm{C}$ for the plate and $475^{\circ} \mathrm{C}$ for the weld metal.

2.2 Mixture Rules and Material Properties. The material properties are computed by assigning temperature dependent properties to each phase. These are combined by using linear mix-

Fig. 2 Thermal properties assigned to each phase
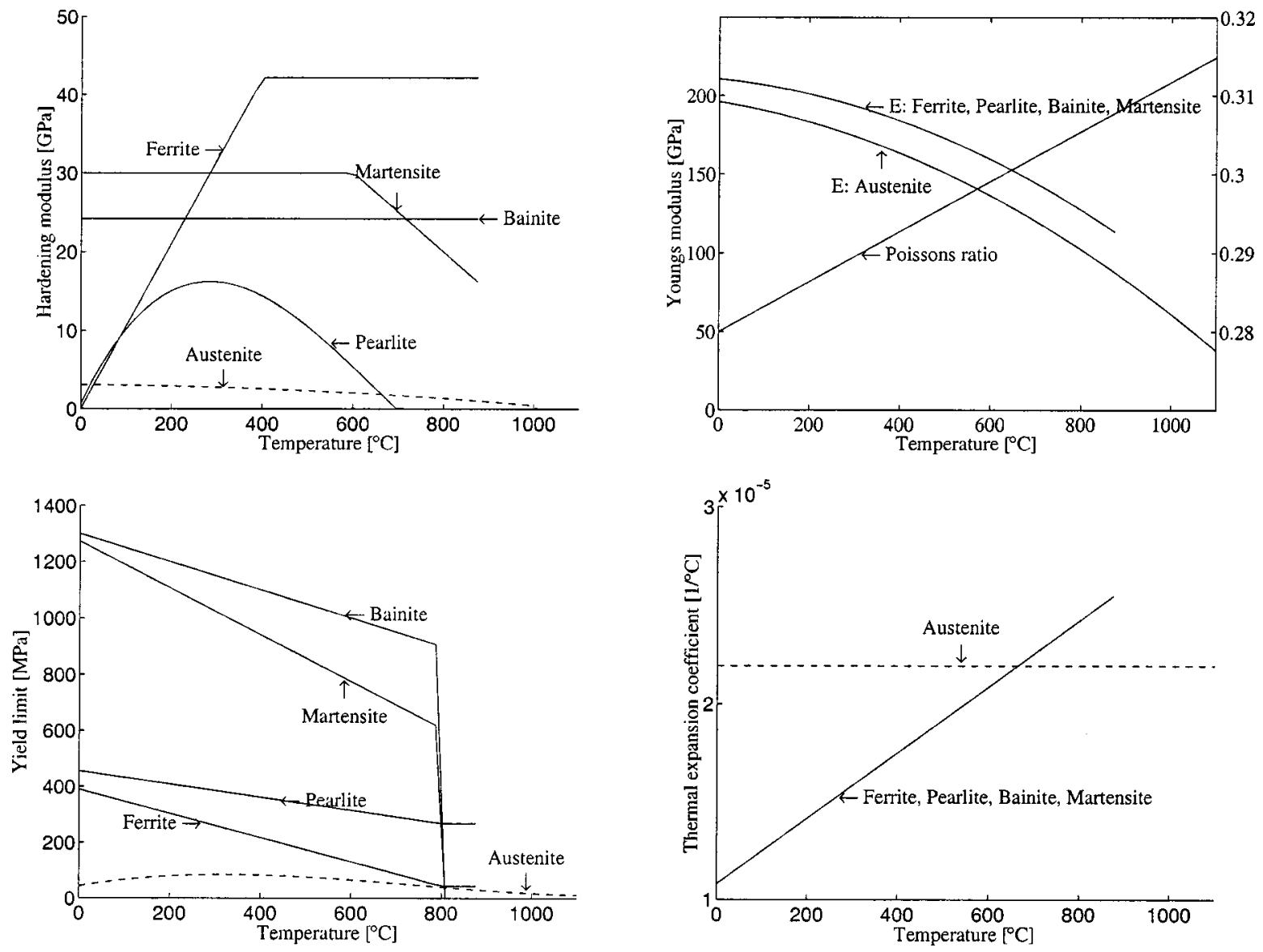

Fig. 3 Mechanical properties assigned to each phase 
Table 2 Latent heat and transformation strain for phase transformation

\begin{tabular}{lcc}
\hline \hline Phase transformation & $\begin{array}{c}\text { Latent heat, } \\
\mathrm{kJ} / \mathrm{kg}\end{array}$ & $\begin{array}{c}\text { Transformation } \\
\text { strain }\end{array}$ \\
\hline austenite $\leftrightarrow$ ferrite, pearlite, bainite & 76 & 0.0081 \\
austenite $\leftrightarrow$ martensite & 82 & 0.0082 \\
\hline \hline
\end{tabular}

ture rules to macro materials properties. The general formula for overall macro properties based on the properties for the different phases is $Y(T, t)=\Sigma_{i} X_{i}(T, t) Y_{i}(T)$

where:

$i=$ austenite, ferrite, pearlite, bainite or martensite

$X_{i}=$ volume fraction of phase $i$

$Y_{i}=$ material property for phase $i$

$Y=$ macro property.

The material properties computed by the mixture rule are heat capacity, heat conductivity, Young's modulus, yield limit, hardening modulus, thermal expansion coefficient and Poisson's ratio. Material properties for each phase are taken from Sjöström [7] who uses a material with similar chemical composition. The same material properties and mixture rules were used for the plate as well as the filler material. Sjöström [7] gives data for a limited temperature range. The temperature range was expanded and the used data can be seen in Figs. 2 and 3. No other phase than austenite will exist above $\mathrm{A}_{\mathrm{e} 3}$ in the used instantaneous austenization model. Therefore properties for ferrite, pearlite, bainite and martensite are not needed above this temperature. Figure 2 shows the thermal material properties and Fig. 3 shows the mechanical properties as a function of temperature for each phase. A cutoff temperature of $1100^{\circ} \mathrm{C}$ was used in this welding simulation. This means that material properties were computed for this temperature when the actual temperature was above the cutoff temperature. The effect of high temperature properties on the residual stresses has been investigated by several authors and found to be small. Tekriwal and Mazumder [8] investigated the effect of varying the cutoff temperature from $600^{\circ} \mathrm{C}$ up to melting temperature. The transverse residual stress was overestimated by from 2 percent -15 percent when the cutoff temperature was lowered. The data from Sjöström give very high hardening modulus for ferrite, pearlite, bainite and martensite. These values has been reduced according to Fig. 3. There are, of course, also uncertainties in other used properties in Figs. 2 and 3 but we have not done any other adjustments of the data obtained from Sjöström [7]. The latent heat of fusion is $260 \mathrm{~kJ} / \mathrm{kg}$ and the latent heats for the solid state phase transformations are given in Table 2. In Table 2 are also the
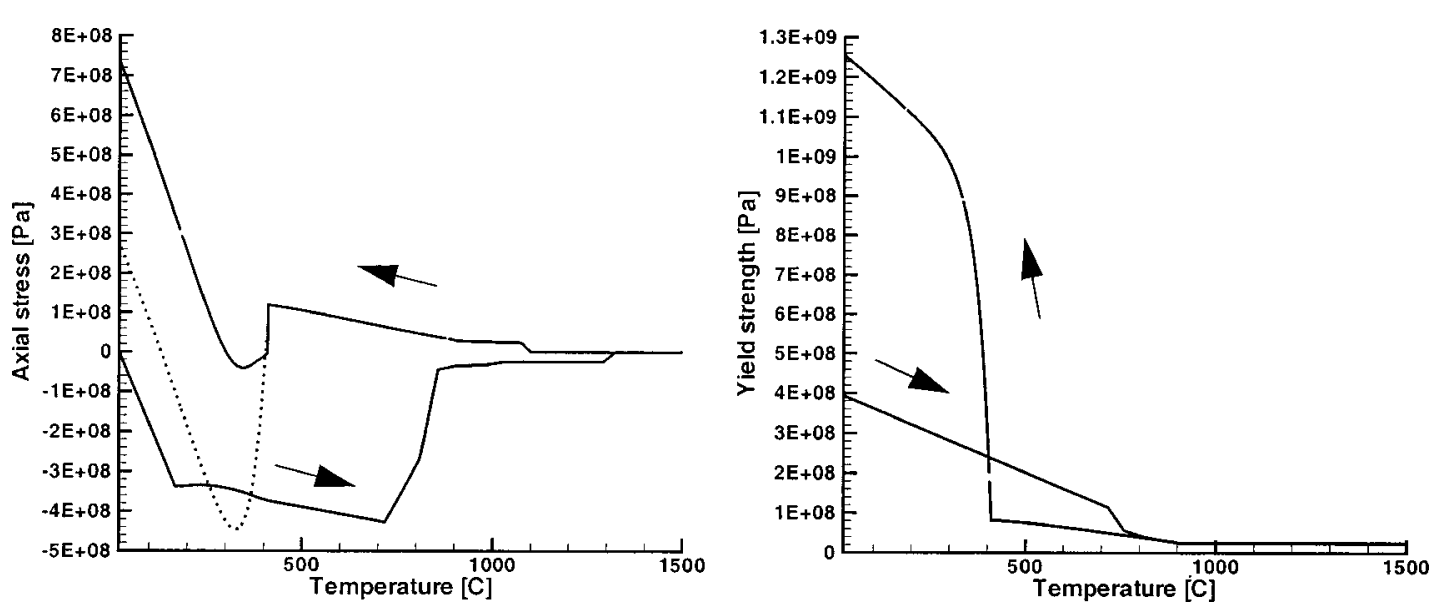

Fig. 5 Computed axial stress with transformation plasticity (solid line) and without transformation plasticity (dashed line) and computed virgin yield strength as a function of temperature

transformation strains given. Transformation strain is a measure of expansion or shrinkage due to phase transformation. This gives in combination with the thermal expansion the total thermal dilatation. $\mathrm{T}_{\text {liquidus }}$ is $1520^{\circ} \mathrm{C}$ and $\mathrm{T}_{\text {solidus }}$ is $1480^{\circ} \mathrm{C}$. No mixture rule was applied for the density. The original density was set to 7800 $\mathrm{kg} / \mathrm{m}^{3}$. It is changing in the analysis due to volumetric strains.

\section{Satoh Test}

A Satoh test has been simulated in order to show the mixture rules. The test specimen is restrained between two rigid walls and exposed to a prescribed heating cycle. Therefore the thermal strain will give uniaxial stress state. Figure 4 shows the computed thermal strain as a function of temperature. The specimen is exposed to a heating from $20^{\circ} \mathrm{C}$ up to $1500^{\circ} \mathrm{C}$ during $20 \mathrm{~s}$ and subsequent cooling during $20 \mathrm{~s}$ to the initial temperature. As can be seen in Fig. 4 the strain increases with increasing temperature due to heat expansion but when the temperature reaches a value high enough for phase transformation the original ferrite and pearlite transforms to austenite which has a less volume than the origin phases. Then there will be a volume decrease for a while to a certain amount. The thermal expansion continues when the transformation is complete until the cut off temperature of $1100^{\circ} \mathrm{C}$ is reached. All properties are assumed to be constant above this temperature. This is also assumed in the welding model in the next section and is discussed at the end of the paper. This means that the only difference between heating to $1100^{\circ} \mathrm{C}$ or to $1500^{\circ} \mathrm{C}$

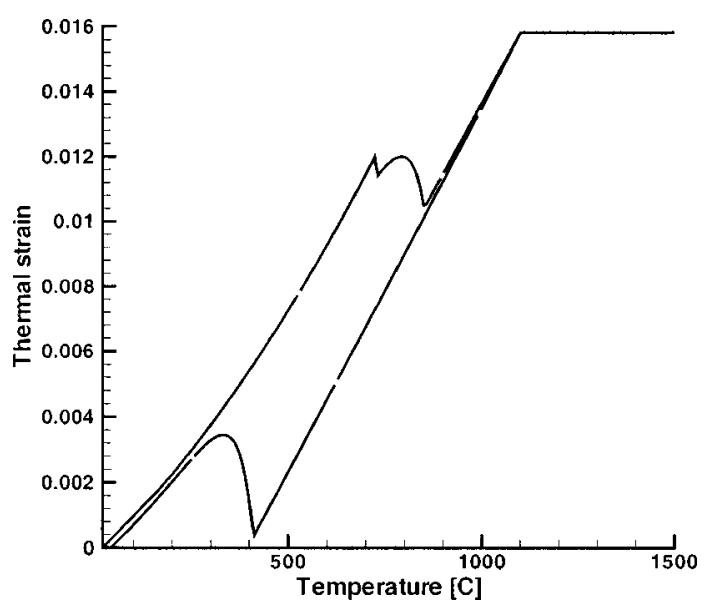

Fig. 4 Computed thermal strain as a function of temperature 
is that the grain growth is larger in the latter case. The heating is then followed by a cooling. If the cooling is fast enough austenite will transform to martensite. This will cause an increase in strain although the temperature is falling as martensite has a larger volume than the original ferrite and pearlite which can be seen in Fig. 4.

Figure 5 shows the axial stress and the virgin yield strength in a Satoh test as a function of temperature. Due to volume expansion the compressive stress is increased with increasing temperature until the yield limit is reached. Then the compressive stress is increasing slowly due to hardening until the transformation from pearlite and ferrite to austenite will cause a decrease in volume and also a decrease in the compressive stress. A cutoff temperature of $1100^{\circ} \mathrm{C}$ was used when computing the stresses in Fig. 5 . The mechanical material properties are then taken for the cutoff temperature if the temperature is higher than this cutoff limit. When the temperature is decreasing there will be a tension in the specimen due to thermal shrinkage. The cooling will cause volume decrease and therefore tension in the specimen. This tension will increase until the austenite decomposes to bainite and martensite which have bigger volume and causes the compressive stress. Further decrease in temperature will give tension in the specimen.

The yield strength decreases with increasing temperature until plastic yielding occurs. This will increase the yield strength due to hardening. When transformation from pearlite and ferrite to austenite occurs the yield strength is decreased due to that austenite has less yield strength than ferrite and pearlite. When $1100^{\circ} \mathrm{C}$ is reached no change in material parameters will occur.

During cooling the yield strength is increasing with decreasing temperature. When the austenite transforms to martensite the yield strength is rapidly increased due to the higher yield strength of martensite. The tensile stress is reduced due to the expansion caused by the martensite. The dashed curve in Fig. 5 shows the axial stress when transformation induced plasticity (TRIP) is not accounted for. The transformation plasticity is not accounted for during heating. This plastic strain reduces the magnitude of the stresses. Further decrease in temperature will increase the yield strength and the importance of the effect of the transformation plasticity on the residual stress is reduced due to large restraint that cause further plastic yielding. The effect of the transformation plasticity is important for the residual stress.

\section{Application to Multipass Welding}

An in-house finite element code, SIMPLE has been used for simulation of the welding. It is described in Lindgren et al. [9]. Temperature dependent plasticity is assumed using von Mises yield criterion and the associated flow rule. Linear isotropic hardening is also assumed. The geometry of the plates and the groove is shown in Fig. 6. The joint was prepared in such a way that an artificial crack appeared in the interior of the groove. The welding is simulated using a 2D-model. Thus the heat flow in the welding direction is neglected and only a cross-section is analyzed. Plane strain is assumed in the mechanical model. The elements that are associated with the weldpasses are included in the simulation when the weldpass starts but given material properties, low Young's modulus and heat capacity, so that they do not affect the solution. They are assigned the melting temperature, $1520^{\circ} \mathrm{C}$, during the time it takes for the arc to pass the analyzed cross section. This time is computed by dividing the estimated length of the weld pool, $3 \mathrm{~cm}$, with the welding speed, $2.5 \mathrm{~mm} / \mathrm{s}$. The surface where the welds are to be laid is preheated to this temperature

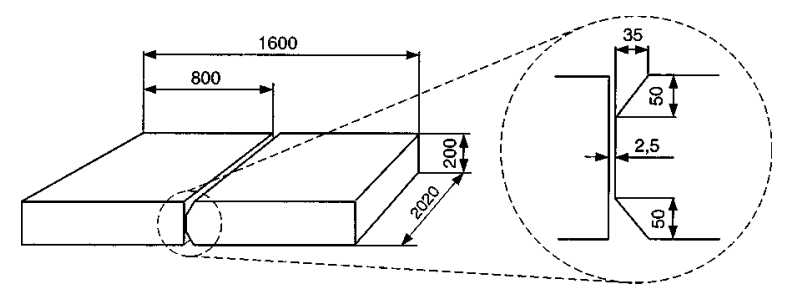

Fig. 6 Geometry of the plates and the groove, distances in $\mathrm{mm}$

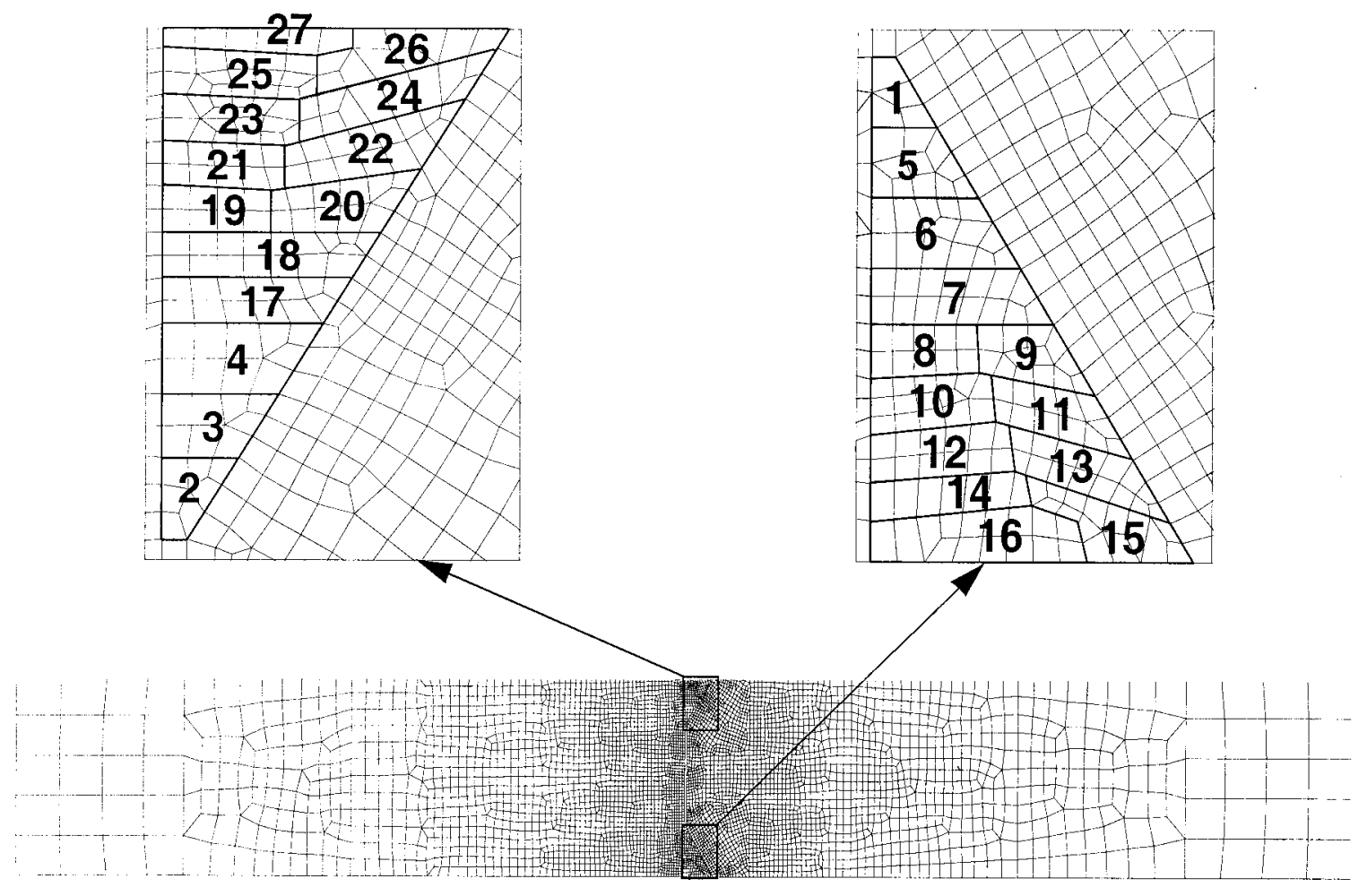

Fig. 7 The mesh and corresponding weldpasses 
during $2.4 \mathrm{~s}$ before the weld is laid as the temperature can not be discontinuous in the model. See Lindgren et al. [9] for further details. Thereafter the weld elements are added to the model and given the prescribed temperature $1520^{\circ} \mathrm{C}$ during another $9.6 \mathrm{~s}$. Thereafter the temperature is not prescribed anymore and the weld cools. The temperature is computed in the usual manner after the arc has passed the cross-section. All other material properties are computed as described earlier. The finite element mesh is shown in Fig. 7. The size of the element where the weldpasses are laid and in the heat affected zone are approximate $2-3 \mathrm{~mm}$. The element size is stepwise increased to $40 \mathrm{~mm}$ further away from the weld. Figure 7 shows the mesh and the corresponding weldpasses.

The model consists of 4710 elements and 4878 nodes when all the welds have been laid. The 27 weldpasses are modelled by 317 elements. Detailed information about addition of new elements for each weldpass and the heat input is given in Lindgren et al. [9]. The total number of time steps is about 2500 and the final time is 60000 seconds. The time step is reduced to $0.1 \mathrm{~s}$ during each weldpass.

\section{Results}

Computed transverse residual stress for a part of the plate is shown in Fig. 8. Computed longitudinal and transverse residual stresses for the upper weld are shown in Fig. 9. Measured and computed residual stresses at the top surface and calculated residual stresses at the bottom surface are shown in Fig. 10. The measurements were performed by the hole drilling method (Measurement Group [10]). The uncertainty in the measurements are $\pm 20 \mathrm{MPa}$ for ideal conditions. Then the stress state should be

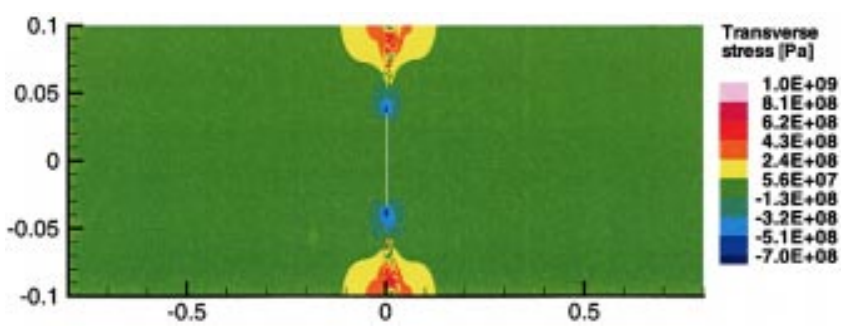

Fig. 8 Transverse residual stress for a part of the plate. Distance in $\mathrm{m}$.

constant in the thickness direction and not higher than half the yield limit. Furthermore, the size of the strain gauges means that the measurements are performed over an area of about $5 \mathrm{~mm}$ in diameter in which the field is also assumed to be constant. Thus it is difficult to estimate the accuracy of the measurements in the current case. The computational model with transformation induced plasticity is referred to as $\mathrm{m} 1$ and without transformation induced plasticity is referred to as $\mathrm{m} 2$ in Fig. 10. Results from Lindgren et al. [9] are also presented in Fig. 10. They use a temperature dependent material model and do not account for temperature history dependency of material properties. Both models give compressive longitudinal and transverse residual stresses around the crack. The calculated final martensite and bainite fractions for the upper weld are shown in Fig. 11. The calculations show that mainly martensite and some bainite is formed in the heat affected zone.
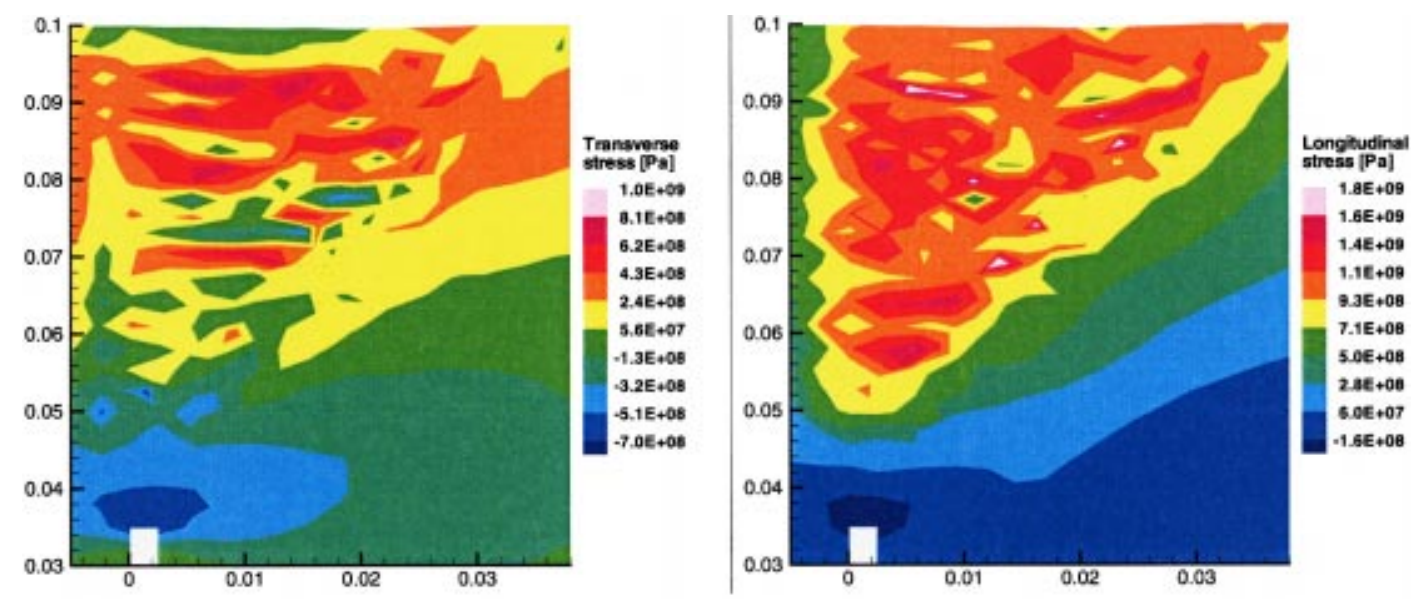

Fig. 9 Transverse residual stress and longitudinal residual stress for welds in upper groove. Distance in $\mathbf{m}$.
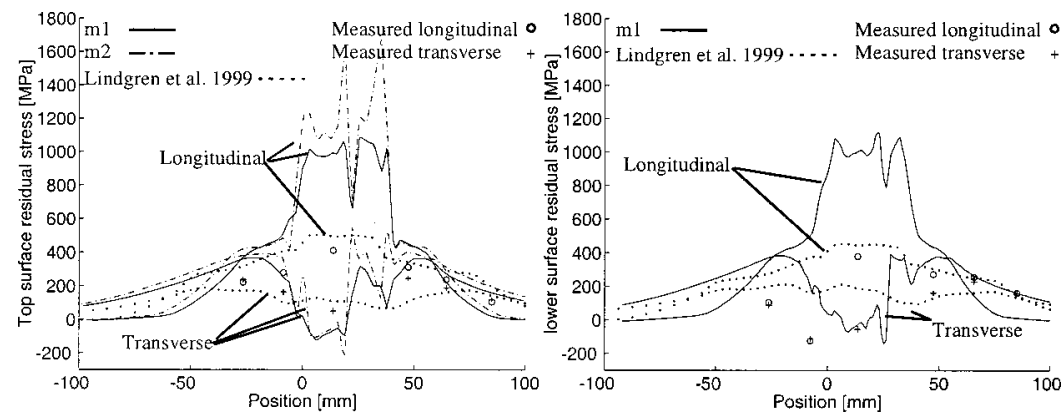

Fig. 10 Calculated and measured residual stress at the top and bottom surfaces. The origin $(x=0)$ is placed at the left side of the joint. 

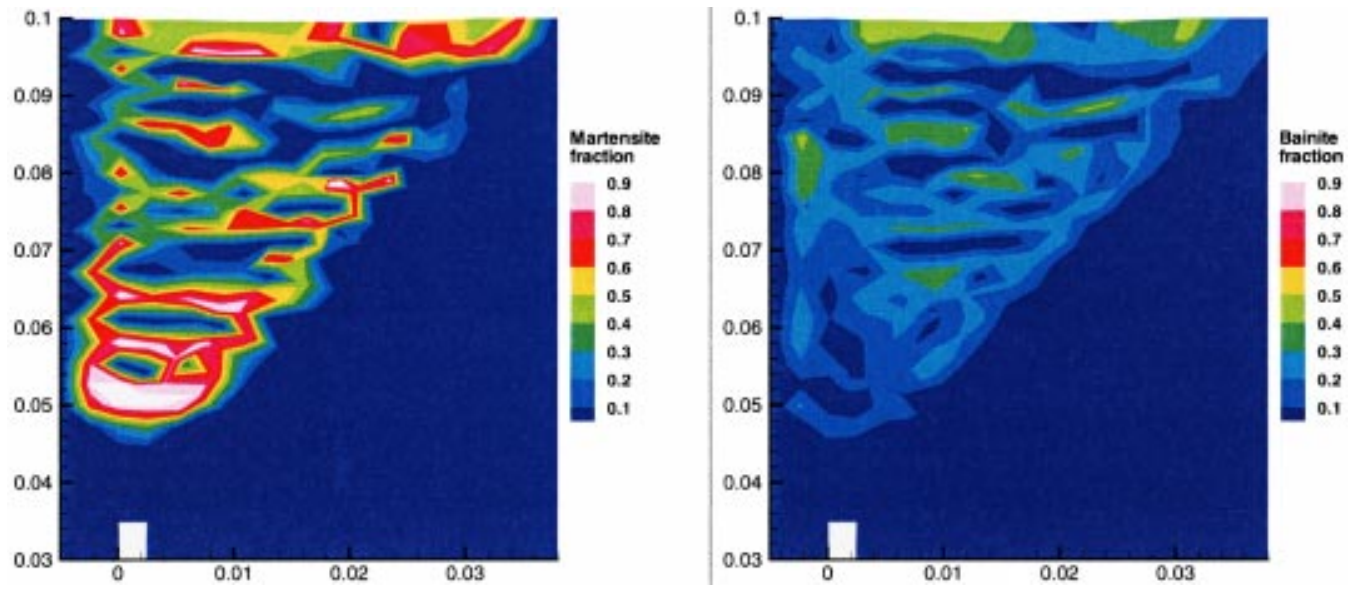

Fig. 11 Final martensite and bainite fractions for welds in upper groove

\section{Discussions and Future Work}

The material model of a multipass welding has been extended to account for temperature history dependent material properties by calculating microstructure evolution and assigning material properties to each phase. The model is in principle an improvement compared to Lindgren et al. [9] where the material properties are only temperature dependent but it does not give a better agreement with measurement. This is caused by the limitation in the used material data for the different phases. Some studies have included kinematic hardening but data was lacking for this study. Lindgren [11] shows that this will effect the residual stress state near the weld even for a one pass weld case. Calculation of residual stresses has been performed both with and without transformation induced plasticity. Transformation plasticity has the effect of reducing the stresses which can be seen in Fig. 9. The computed residual transverse stress shows good agreement with experimental values. The agreement is poorer for residual longitudinal stress. This depends on the plain strain model used in the computations. The error introduced by ignoring the heat flow in this direction is small (Andersson [12]) but the mechanical restraint due to the plane strain assumption gives a too high longitudinal residual stress (McDill et al. [13]). The model can be improved by a more detailed modelling of phase material properties and using a nonlinear mixture rule. A three-dimensional model of this problem is still to large to be used in a simulation.

\section{References}

[1] Karlsson, L., 1997, “Modeling in Welding, Hot Powder Forming and Casting," ASM International, ISBN: 0-87170-616-4.

[2] Inoue T., and Wang Z. G., 1983, "High-Temperature Behavior of Steels with
Phase Transformation and the Simulation of Quenching and Welding Processes," Proc. of 4th Int. Conf. Mechanical Behavior of Materials, Stockholm, Sweden, Aug., pp. 1015-1021.

[3] Bergheau J. M., and Leblond J. B., 1991, "Coupling Between Heat Flow, Metallurgy and Stress-Strain Computations in Steels: The Approach Developed in the Computer Code Sysweld for Welding and Quenching," Proc. of the 5th Int. Conf. Modelling of Casting, Welding and Advanced Solidification Processes, The Minerals, Metals \& Materials Society, pp. 203-210.

[4] Oddy, A. S., McDill, J. M. J., and Karlsson, L., 1996, "Microstructural predictions including arbitrary thermal histories reaustenization, and carbon segregation effects,' Can. Metall. Q., 35, No 3, pp. 275-283.

[5] Kirkaldy, J. S., and Venugopalan, D., 1983, 'Prediction of Microstructure and Hardenability in Low Alloy Steels," Proc. Int. Conf. on Phase Transformations in Ferrous Alloys, Marder A. R., and Goldstein, J. R., eds., Philadelphia, Oct. pp. $125-148$

[6] Börjesson, L., and Lindgren, L-E., 1997, "Residual Stresses and Microstructure Computation for Multipass Welding,'” ICRS-5, pp. 189-194, Linköping, Sweden.

[7] Sjöström, S., 1982, "The calculation of quench stresses in steel," thesis no 84, Univ. of Linköping, Sweden.

[8] Tekwriwal, P., and Mazumder, J., 1991, "Transient and residual thermal strain-stress analysis of GMAW," ASME J. Eng. Mater. Technol., 113, pp. 336-343.

[9] Lindgren, L-E., Runnemalm, H., and Näsström, M., 1999, "Simulation of multipass welding of a thick plate,' Int. J. Numer. Methods Eng., 44, pp. $1301-1316$.

[10] Measurement Group, 1985, "Measurement of residual stresses by the hole drilling strain-gage method," TN-503-1, Raleigh North Carolina, USA.

[11] Lindgren, L-E., 1999, “A welding simulation revisited,' 3rd Int. Congress on Thermal Stresses, Cracow, Poland, June.

[12] Andersson, B. A. B., 1978, “Thermal stresses in a submerged-arc welded joint considering phase transformations,' ASME J. Eng. Mater. Technol., 100, pp. $356-362$

[13] McDill, J. M. J., Oddy, A. S., and Goldak, J. A., 1992, “'Comparing 2-D plane strain and 3-D analyses of residual stresses in welds," Proc. of 3rd International Conference on Trends in Welding Research, Gatlinburg, Tennessee, June. 